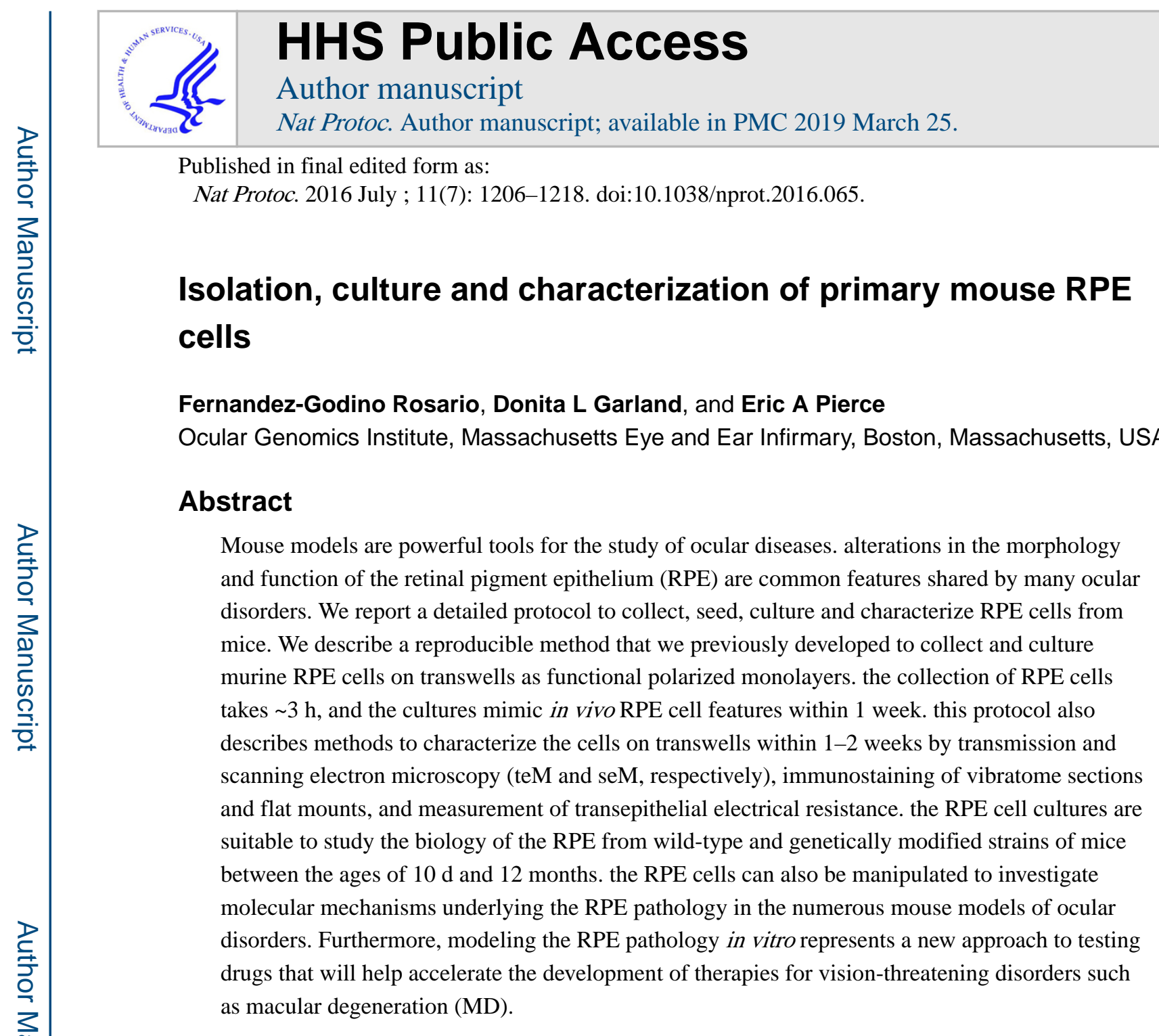

\title{
INTRODUCTION
}

The RPE is located between the choroid and the neural retina ${ }^{1}$, sitting on a five-layered extracellular matrix called the Bruch's membrane. The RPE is a monolayer of polarized cells joined by tight junctions that have a critical role in the maintenance of the retina and visual cycle ${ }^{1-4}$. The main functions of the RPE are the nourishment of photoreceptors, the absorption of dispersed light, the phagocytosis of shed outer segments from photoreceptor cells and the transport of electrolytes between the retina and the choroid ${ }^{1,5,6}$. The RPE also has an important role in local modulation of the immune system in the eye $\mathrm{e}^{7-12}$.

RPE dysfunction caused by genetic disorders or age-related changes contributes to many ocular disorders, including retinitis pigmentosa, Leber congenital amaurosis, albinism, diabetic retinopathy and $\mathrm{MDs}^{8,13-20}$. Although it would be ideal to study these disorders in

Reprints and permissions information is available online at http://www.nature.com/reprints/index.html.

Correspondence should be addressed to R.F.-G. (rosario_godino@meei.harvard.edu).

AUTHOR CONTRIBUTIONS R.F.-G. conceived of, designed and performed experiments and wrote the manuscript. D.L.G. and

E.A.P designed the experiments and edited the manuscript.

COMPETING FINACIAL INTERESTS The authors declare no competing financial interests. 
human RPE cells, it is difficult to obtain RPE cells from documented donors because such disorders do not necessarily carry an increased risk of mortality ${ }^{14,21}$. Transgenic rats are also a good approach, but mouse models are more numerous because the transgenic technology is more widely established in this species ${ }^{22}$. The use of cultured primary RPE cells provides advantages such as genetic manipulation, but it has been difficult with current techniques to reproducibly obtain cultures of primary mouse RPE cells that have features of RPE cells in vivo. Cells tend to lose hexagonal shape and transepithelial electrical resistance (TER) within a few days in culture, and it has been difficult to culture RPE cells from adult mice $^{14,23}$.

\section{Development of the protocol}

Some groups have described the isolation of RPE sheets from human and rat eyes by peeling them off the choroid ${ }^{24-27}$. However, mouse RPE sheets are too small, and the damage caused by manipulation with forceps leads to the death of many cells. Hence, mechanical dissociation may work for other purposes, such as RNA studies, but it is not the best approach for RPE cultures ${ }^{13}$. We considered that the use of enzymatic digestion and gentle dissociation without forceps would reduce cell death and help further proliferation of the RPE cells in culture ${ }^{28-30}$. Hyaluronidase and dispase had been previously used to detach RPE from neural retina in rat and human eyes, but it did not help with the additional detachment of RPE from choroid $13,23,25,26,28,29,31$. Thus, after removal of the neural retina, the use of trypsin proved to be the best approach to break cell-cell interactions within eyecups ${ }^{29}$. By modifying existing protocols, we optimized the incubation time and trypsin concentration, which resulted in large, uninjured RPE sheets detaching from eyecups after gentle shaking ${ }^{29,30}$.

\section{Applications of this method}

We have recently published a paper on the use of our improved protocol to culture primary RPE from a mouse model of EFEMPlassociated MD. The study showed that the RPE cells grown in vitro recapitulated the pathology observed in vivo and helped to clarify the role of the immune system in EFEMP1-associated MD ${ }^{12,32,33}$. More specifically, we showed that $\mathrm{C} 3 \mathrm{a}$, which is produced from local activation of complement by the RPE, is involved in the formation of basal deposits in EFEMP1-associated $\mathrm{MD}^{12}$.

The method described here allows - for the first time, to our knowledge - the isolation and culture of RPE cells from a single mouse, thus keeping the biological variability among samples. This protocol can be used to isolate RPE cells from mice from any genetic background, including albino, and it has been successfully applied to culturing RPE from mice of various ages between $10 \mathrm{~d}$ and 12 months. This allows the study of mechanisms that take place at different stages of the RPE pathology. Therefore, this protocol can be applied to any of the existing mouse models of human ocular diseases, such as Stargardt disease, conerod dystrophy, retinitis pigmentosa and so on ${ }^{34-36}$. Moreover, this protocol will be very valuable for testing the increasing numbers of mouse models that are currently being created using the novel CRISPR/Cas9 approach $^{37,38}$. 
The RPE cells are cultured on laminin-coated Transwell permeable supports instead of plates to maintain their barrier properties and to create polarized RPE cells in vitro. Polarized RPE cells can be characterized by the presence of apical microvilli and basal infoldings, and differential secretion of proteins to the apical and basal compartments. RPE cells that are grown on Transwells represent a valuable system for studying RPE transport, protein localization and function, and RPE response to external molecules or drugs added to the apical or basal medium ${ }^{12}$. Furthermore, laminin-coated Transwells allow the accumulation of substances under the RPE as occurs in the formation of basal deposits in age-related macular degeneration (AMD) $\mathrm{AMD}^{12}$. Consequently, this method can be used to identify potential therapeutic targets for the treatment of MDs, as well as other ocular diseases that involve the RPE. In addition, the RPE culture is a unique system for evaluating the toxicity and efficacy of existing drugs. For instance, complement-modulating drugs can be tested in vitro in order to analyze their ability to inhibit/ delay the formation of sub-RPE deposits in MDs ${ }^{12}$.

\section{Comparison with other methods}

To date, only a few methods for RPE isolation and culture from mice have been developed ${ }^{14,23,28-30,39}$. However, these methods tend to produce cells that do not reach total confluence and that lose their characteristic hexagonal shape and pigmentation ${ }^{30,40}$. Furthermore, previously described methods used serum in the medium; this is inconvenient for complement-related studies because serum contains bovine complement proteins that may interfere with the results. With our protocol, cells retain their hexagonal shape and pigmentation, and they can be maintained in culture for at least 2 months, even in the absence of serum. We have designed this protocol to collect RPE cells from mice at any age from $10 \mathrm{~d}$ to 12 months, compared with previous protocols that were designed for 10- to 15d-old mice ${ }^{13,14,23,29}$. RPE cells from older mice do not appear to divide in culture, but the majority ( $80 \%)$ of the cells survive and are able to organize into a monolayer in vitro after the isolation process.

One important variation in our protocol as compared with others is the use of hyaluronidase to detach the neural retina from the RPE layer. Some protocols for the isolation of human RPE cells use dispase, but we have found that hyaluronidase is less toxic to mouse RPE cells $^{23,25}$. Bonilha et al ${ }^{28}$ introduced the use of hyaluronidase to isolate RPE cells from rat eyes after removal of the iris epithelium. However, we have found that incubation of the eye with hyaluronidase after lens removal, while the cornea and iris epithelium are still in place, allows the exposure of the neural retina to enzymatic digestion without exposing the underlying RPE. Subsequent incubation on ice helps the neural retina to shrink, making it easier to separate the photoreceptors from the RPE after digestion.

Another key modification with respect to previous protocols is the use of enzymatic digestion to separate the RPE from the Bruch's membrane ${ }^{14,23}$. Nandrot et al. ${ }^{29}$ use a high concentration of pure trypsin $(2 \mathrm{mg} / \mathrm{ml})$ to peel off the RPE from the choroid. We have improved upon this method, using only one-tenth the concentration of trypsin, with the addition of EDTA, which removes $\mathrm{Ca}$ and $\mathrm{Mg}$ ions and facilitates cell detachment. Furthermore, we shake the eyecup to detach the RPE sheets, instead of manually peeling 
them. Enzymatic digestion using a reduced trypsin concentration combined with shaking to detach the RPE sheets is gentler, resulting in greater cell survival and allowing the cultures to reach high cell density ${ }^{12}$. We then seed the isolated RPE cells as single cells, which ultimately form confluent monolayers in vitro, rather than maintaining the original sheets that were formed in the eye ${ }^{29}$. We consider these conditions to be key to the ability of RPE cultures to proliferate and recapitulate in vivo features.

Mouse RPE cultures developed via our method perform better than others at maintaining polarization in monolayer, as demonstrated by structural studies and polarized secretion of substances such as cytokines ${ }^{12}$. Integrity of the RPE monolayer is also indicated by a relatively high TER and the expression of the tight-junction protein ZO-1 (refs. 2,4,41,42). TER values measured in our cultures are ten times higher than those previously published for primary mouse RPE cultures and closer to values found in primary human RPE cell cultures $^{12,14,25,26,43}$. High TER values imply that the RPE cells have paracellular resistance and maintain their function as a barrier ${ }^{44}$. In addition, the tight-junction protein ZO- 1 is evenly expressed from the first week in culture. On the basis of the morphology, physiology and TER found in our RPE cultures, this in vitro system faithfully mimics features of mouse RPE in vivo ${ }^{12}$. Overall, our protocol provides a method for the collection and culture of mouse RPE cells from single adult animals that produces confluent polarized RPE monolayers in less than 1 week.

\section{Limitations of the protocol}

One disadvantage of this method is the amount of time needed to obtain multiple cultures. Given that RPE from only two mice should be isolated simultaneously, it may take several days to collect all the required RPE for experiments that require replicates or high amounts of sample, such as proteomic analyses. However, the mice used in this protocol can be adults, with fully mature eyes, so there is no need to pool more than two eyes per Transwell or to expand the cells through several passages, as is done with other protocols ${ }^{14,23}$. Thus, for experiments in which biological variability is key, such as RNA-seq or drug treatments, this protocol resembles the conditions in vivo more accurately. In addition, after performing the protocol many times, the user will acquire the speed and skill to handle up to 4-6 eyes simultaneously by alternating incubation times.

Furthermore, a major limitation of this protocol is that RPE cells cultured in vitro cannot be expanded. To maintain the high TER and pigmentation, only passage 0 cells should be used. After extensive time in culture or after being split with trypsin, mouse RPE cells tend to lose pigmentation and acquire a fibroblastic shape, losing the properties that resemble in vivo features. In addition, given the small amount of material that can be obtained from one culture, samples may need to be pooled for experiments such as proteomic analyses, in which relatively large amounts of starting material are required.

\section{Experimental design}

Preparation of the Transwells.-We use laminin to coat our Transwells; other coating materials such as FBS and gelatin have been found to work as well, although laminin coating has been shown to produce the most uniform cultures. However, if animal models 
that are defective in some extracellular matrix genes are used, Matrigel or other coating substances may work better ${ }^{45}$. Our protocol describes the use of $6.5-\mathrm{mm}$ Transwells. Although larger Transwells have also worked for us, we have found that the $6.5-\mathrm{mm}$ Transwells produced the most uniform and reproducible cultures. We have observed that pooled RPE cells grown on 12-mm Transwells may show uneven distribution, resulting in a higher percentage of cell death. The cultures may be more confluent around the edges than in the center of the Transwell, and multilayered cultures may form.

Mice.-Typically, 8- to 12-week-old mice are used, although the method has proven successful with mice of various ages and seven different genetic backgrounds, including albino mice. However, it is important to remark that RPE cells from old mice do not proliferate, and younger mice have smaller eyes with fewer cells, so more eyes may need to be pooled.

Typically, we euthanize mice by $\mathrm{CO}_{2}$ asphyxiation; however, decapitation would also work and may be preferable for pups and cultures in which oxidative stress will be studied. With our system, each mouse is considered a different culture; both eyes from the same mouse are pooled in a $6.5-\mathrm{mm}$ Transwell, maintaining the biological variability. RPE collection should be done immediately after enucleation. To improve cell survival, we recommend enucleating only two eyes at a time, at least until some experience is acquired, given that cells sitting on ice for long periods of time will die. We never leave the cells on ice for more than $45 \mathrm{~min}$. Dissecting skills can be acquired only with experience; thus, the first dissections may result in accidental injuries to the sclera and neural retina. We recommend performing a number of dissections to acquire dexterity.

Collection of the RPE.-Approximately $80 \%$ of the RPE cells of each eye will result in highly polarized RPE monolayers. Twenty-four hours after seeding, most of the cells will be attached to the insert of the Transwell (Fig. 1a), and typical morphology of RPE monolayers will be visible after $72 \mathrm{~h}$ in culture. After 2 weeks, the honeycomb is fully formed and cell cultures resemble RPE in vivo (Fig. 1b).

We have found that the size of the RPE sheets that detach after incubation with trypsin varies from eye to eye. However, we have determined experimentally that RPE sheets are smaller and are more difficult to detach when the trypsin is not fresh. Thus, we freeze small aliquots $(\sim 8 \mathrm{ml})$ of $0.25 \%$ trypsin $+0.02 \%$ EDTA (vol/vol) and thaw them before each use.

Confluence and morphology.-Confluence of the cells at seeding is fundamental for the formation of a suitable RPE monolayer. That is, low confluence or a high rate of cell death will cause the remaining cells to spread and lose their pigmentation and polarization, and to acquire a fibroblast-like morphology (Fig. 1c), whereas an excess of cells will cause multilayered cultures. Furthermore, confluence of the RPE cultures is key to reaching polarization and a high TER. In our experience, when the size of the RPE sheets is small or cells mainly detach as single cells, it results in a low-confluence culture. In that case, pooling three eyes of the same genotype and litter will result in good-quality, confluent cultures. 
Our method of isolation and seeding helps the RPE grow as a monolayer of hexagonal, pigmented, polarized and bi-nucleate cells (Fig. 1b). The cells need to be grown in the presence of 5\% FBS for the first $72 \mathrm{~h}$. After that, cells can be maintained with or without serum for extended periods of time. In our laboratory, cells can grow over 6 weeks without changes in morphology or viability.

Twenty-four hours after seeding, most of the live cells should be attached to the insert, and two nuclei per cell should be visible as cleared spots in a pigmented cytoplasm (Fig. 1a). The average number of RPE cells obtained from two eyes from a mouse aged 2-3 months old is $\sim 50,000$, using a $6.5-\mathrm{mm}$ Transwell. Older mice may result in a higher number, but differences are insignificant. Sometimes attachment of the cells to the surface may take longer. For this reason, it is recommended that the medium not be changed for the first $72 \mathrm{~h}$. After $72 \mathrm{~h}$, the attachment is strong enough and the cells will not detach when the medium is aspirated. During the next few days, the cells will expand while maintaining their pigmentation, and after 1 week they will reach confluence (Fig. 1b). Cells tend to expand to reach neighbor cells, so their size varies among cultures. For this reason, we measure confluence rather than the number of cells.

Cells that are very large and very dark (Fig. 1d) will not develop a high TER and should be discarded. Once cells are confluent, they may be split into new Transwells precoated with laminin, using $0.05 \%$ trypsin-EDTA; however, large dilutions are not recommended, as splitting of cells produces a decrease in confluence that may result in loss of pigmentation, hexagonal shape and polarization.

Characterization of the RPE cultures.-SEM images will help to visualize the hexagonal shape and the presence of microvilli on the apical surface. On the other hand, TEM images will show the presence of apical microvilli, basal infoldings, melanin pigments, tight junctions between cells and healthy organelles.

RPE cells from mouse models of ocular disorders are commonly used to study the mechanisms of disease in vitro. Many pathologies cause dysfunction of the RPE monolayer that can be demonstrated by changes in the expression of some proteins. Immunostaining is key to assaying the expression of intracellular proteins. However, apical melanin granules inside RPE cells cause high pigmentation that may mask fluorescence in flat mounts. The use of vibratome sections will help to visualize proteins localized in the cytoplasm, as well as in the cellular membrane.

This protocol can be implemented by any investigator or technician after some practice. It does not require any special facilities other than a cell culture incubator and a laminar flow hood. One person can perform the whole protocol from the beginning to the end.

\section{MATERIALS}

REAGENTS

- 2- to 3-month-old mice. We have used mice from different genetic backgrounds, i.e., C57BL/6J and C57BL/10Sn, but this protocol is suitable for use on any type 
of mouse ! CAUTION Any experiments involving live mice must conform to relevant institutional and national regulations. In our experiments, the guidelines of the ARVO (The Association for Research in Vision and Ophthalmology) Statement for the Use of Animals in Ophathalmic and Vision Research were followed. The use of mice in this study was approved by the Massachusetts Eye and Ear Infirmary Animal Care and Use Committee and followed the ARRIVE guidelines ${ }^{46}$.

- $\quad$ Ethanol (Sigma-Aldrich, cat. no. E7023-500ML)

- $\quad$ Hyaluronidase (Sigma-Aldrich, cat. no. H-3506 1G)

- HBSS no calcium, no magnesium, no phenol red (HBSS-; Life Technologies, cat. no. 14175095$)$

- HBSS plus calcium and magnesium, no phenol red (HBSS+; Life Technologies, cat. no. 14025092)

- $\quad$ Dulbecco's PBS no calcium, no magnesium (PBS 1×; Gibco, cat. no. 14190144)

- $\quad$ Laminin, $1 \mathrm{mg} / \mathrm{ml}$ (Sigma-Aldrich, cat. no. L2020-1 MG)

- $\quad$ FBS (Hyclone, cat. no. SH30071.03) A CRITICAL We have observed that the cells do not perform well with other brands of FBS.

- $\quad$ RPE culture medium (see REAGENT SETUP)

- $\quad$ Alpha minimum essential medium (alpha MEM; Sigma-Aldrich, cat. no. M4526-500ML)

- $\quad$ Non-essential amino acids, $100 \times($ Gibco, cat. no. 11140050)

- $\quad$ L-Glutamine (Gibco, cat. no. 25030081)

- $\quad$ Penicillin-streptomycin (Gibco, cat. no. 15140-148)

- $\quad$ Taurine (Sigma-Aldrich, cat. no. T-0625)

- $\quad$ Hydrocortisone (Sigma-Aldrich, cat. no. H-0396)

- $\quad$ Triiodo-thyronin (Sigma-Aldrich, cat. no. T-5516)

- $\quad 0.05 \%$ Trypsin-EDTA (1×), phenol red (Gibco, cat. no. 25300054)

- $\quad 32 \%(\mathrm{vol} / \mathrm{vol})$ paraformaldehyde (PFA; formaldehyde) aqueous solution (Electron Microscopy Sciences, cat. no. 15714) ! CAUTION PFA is considered toxic, and it should be manipulated inside a hood and discarded as hazardous waste.

- $\quad 25 \%$ EM-grade aqueous glutaraldehyde in serum vial (Electron Microscopy Sciences, cat. no. 16216) ! CAUTION Glutaraldehyde is considered toxic, and it should be manipulated inside a hood and discarded as hazardous waste.

- $\quad$ Sodium cacodylate (Polysciences, cat. no. 01131) ! CAUTION Sodium cacodylate is considered toxic, and it should be manipulated inside a hood and discarded as hazardous waste. 
- $\quad$ Calcium chloride (Sigma-Aldrich, cat. no. C1016-100G)

- $\quad$ Uranyl acetate (Polysciences, cat. no. 00379)

- $\quad$ Sodium tetraborate (Millipore, cat. no. 106308)

- $4 \%$ (vol/vol) osmium tetroxide (Polysciences, cat. no. 0972A) ! CAUTION Osmium tetroxide is considered toxic, and it should be manipulated inside a fume hood and discarded as hazardous waste.

- $\quad$ Toluidine blue stain $(0.05 \%)$ (Polysciences, cat. no. 1234)

- $\quad$ Low viscosity embedding kit (Electron Microscopy Sciences, cat. no. 14300)

- Rabbit anti ZO-1 (Invitrogen, cat. no. 40-2300)

- Hoechst 33342 , trihydrochloride, trihydrate - $10 \mathrm{mgml}$ solution in water (Invitrogen, cat. no. H3570)

- $\quad$ Fluoromount G (Electron Microscopy Sciences, cat. no. 17984-25)

- $\quad$ Agarose type XI (Sigma-Aldrich, cat. no. A3038)

\section{EQUIPMENT}

- $\quad$ Tissue-culture-treated six-well plates (Fisher Scientific, cat. no. 14-832-11)

- $\quad$ Tissue-culture-treated 12-well plates (Fisher Scientific, cat. no. 08-772-29)

- $\quad$ Tissue-culture-treated 24-well plates (Fisher Scientific, cat. no. 50-202-139)

- $\quad$ 15-ml centrifuge tube (VWR International, cat. no. 21008-103)

- $\quad$ 50-ml centrifuge tube (VWR International, cat. no. 21008-951)

- Falcon Easy-Grip Clear Polystyrene Cell Culture Dish, 35 mm (BD Biosciences, cat. no. 353001)

- $\quad$ McPherson-Vannas micro scissors, $8 \mathrm{~cm}$ long (WPI, cat. no. 503216)

- Dumont \#5 $45^{\circ}$ Medical Biology tweezers, $0.05 \times 0.01 \mathrm{~mm}$ tip, $11 \mathrm{~cm}$ length (WPI, cat. no. 14101)

- $\quad$ Angled microforceps (WPI, cat. no. 501727-G)

- Vannas scissors, $8 \mathrm{~cm}$ long, stainless steel (WPI, cat. no. 501790)

- $\quad$ Tweezer, Dumont \#5 Medical Biology $11 \mathrm{~cm}$, curved, stainless steel, $0.02 \times 0.06$ mm mod tips (WPI, cat. no. 500232)

- $\quad$ Sterile Bard-Parker carbon steel surgical blade, size 11 (Fisher Scientific, cat. no. 08-914B)

- Whatman Puradisc 25-mm syringe filters, $0.45-\mu \mathrm{m}$ pore size (Fisher Scientific, cat. no. 6780-2504)

- $\quad$ 10-ml BD Luer-Lok tip syringe, disposable (BD Biosciences, cat. no. 309604)

- $\quad$ Sterile serological pipette, $25 \mathrm{ml}$ (Fisher Scientific, cat. no. 07-200-575) 
- Sterile serological pipette, $10 \mathrm{ml}$ (Fisher Scientific, cat. no. 07-200-574)

- $\quad$ Sterile serological pipette, $5 \mathrm{ml}$ (Fisher Scientific, cat. no. 07-200-573)

- $\quad$ Sterile serological pipette, 2 ml (Fisher Scientific, cat. no. 07-200-572)

- $\quad$ Sterile serological pipette, $1 \mathrm{ml}$ (Fisher Scientific, cat. no. 07-200-571)

- $\quad$ Dissecting microscope (Leica model M80 or similar)

- $\quad$ Leica DM IL inverted contrasting microscope for living cell applications (Leica)

- $\quad$ Transwell supports, 6.5 mm (Sigma-Aldrich, cat. no. CLS3470-48EA)

CRITICAL Transwells must contain a polyester insert. Cells do not attach to inserts made of other materials.

- $\quad$ EVOM epithelial tissue voltohmmeter (WPI, cat. no. EVOM2)

- $\quad$ Eppendorf 5810R centrifuge (Eppendorf)

- $\quad$ Leica TCS SP5 confocal laser-scanning microscope (Leica)

- $\quad$ Ion beam coater (Gatan model no. 681)

- $\quad$ SAMDRI-795 semi-automatic critical point drier (Tousimis)

- JEOL JSM-7401F scanning electron microscope (Jeol)

- $\quad$ FEI TECNAI G2 Spirit transmission electron microscope (FEI)

- $\quad$ Humidity chamber tray (Sigma-Aldrich, cat. no. Z670146)

- $\quad$ Leica UC7 Ultramicrotome (Leica)

\section{REAGENT SETUP}

HBSS-H- (HBSS without calcium, without magnesium buffer + 10 mM HEPES) Add 1 $\mathrm{ml}$ of $1 \mathrm{M}$ HEPES to $99 \mathrm{ml}$ of HBSS- (without $\mathrm{Ca} / \mathrm{Mg}$ ) buffer. This buffer can be stored at $4{ }^{\circ} \mathrm{C}$ for 1 month.

HBSS-H+ (HBSS with calcium, with magnesium buffer + $10 \mathrm{mM}$ HEPES) Add $1 \mathrm{ml}$ of $1 \mathrm{M}$ HEPES to $99 \mathrm{ml}$ of HBSS+ (with $\mathrm{Ca} / \mathrm{Mg}$ ) buffer. This buffer can be stored at $4{ }^{\circ} \mathrm{C}$ for 1 month.

Hyaluronidase solution (1 $\mathbf{~ m g} / \mathbf{m l})$ Add $10 \mathrm{mg}$ of hyaluronidase to $10 \mathrm{ml}$ of HBSS-H- and filter it with a $0.4-\mu \mathrm{m}$ sterile syringe filter. Prepare fresh hyaluronidase solution each time, and leave it at room temperature (RT; $\left.20-25^{\circ} \mathrm{C}\right)$ until use.

FBS solution FBS solution is prepared by mixing 20\% FBS with HBSS-H+. Add $2 \mathrm{ml}$ of FBS to $8 \mathrm{ml}$ of HBSS-H+. This solution should be freshly prepared before use.

RPE medium RPE medium is N1 Medium Supplement 1/100 (vol/vol), glutamine 1/100 ( $\mathrm{vol} / \mathrm{vol})$, penicillin-streptomycin $1 / 100$ ( $\mathrm{vol} / \mathrm{vol}$ ) and nonessential amino acid solution $1 / 100$ ( $\mathrm{vol} / \mathrm{vol})$, hydrocortisone $(20 \mu \mathrm{g} / \mathrm{l})$, taurine $(250 \mathrm{mg} / \mathrm{l})$ and triiodo-thyronin $(0.013$ $\mu \mathrm{g} / \mathrm{l})$ in alpha MEM (ref. 25) + 5\% FBS or without FBS. RPE medium should be freshly 
prepared for RPE isolation. If desired, FBS may be heat-inactivated; no differences have been observed. For cell culture maintenance, RPE medium can be stored at $4{ }^{\circ} \mathrm{C}$ for up to 1 month.

4\% (vol/vol) PFA Dilute $1 \mathrm{ml}$ of $32 \%$ (vol/vol) PFA in $7 \mathrm{ml}$ of PBS. This solution should be freshly prepared each time.

1\% (vol/vol) glutaraldehyde Dilute $0.4 \mathrm{ml}$ of $25 \%$ (vol/vol) glutaraldehyde in $9.6 \mathrm{ml}$ of PBS. This solution should be freshly prepared each time.

Cacodylate buffer Dissolve $4.28 \mathrm{~g}$ of sodium cacodylate in $100 \mathrm{ml}$ of $\mathrm{dH}_{2} \mathrm{O}$. Adjust the $\mathrm{pH}$ to 7.2-7.4. This solution can be stored at $4{ }^{\circ} \mathrm{C}$ for 1 month.

Half-strength Karnovsky's fixative Mix $6.25 \mathrm{ml}$ of 32\% (vol/vol) PFA, $10 \mathrm{ml}$ of 25\% (vol/ vol) glutaraldehyde, $50 \mathrm{ml}$ of $0.1 \mathrm{M}$ cacodylate buffer, $12.5 \mathrm{ml}$ of calcium chloride and $21.25 \mathrm{ml}$ of $\mathrm{dH}_{2} \mathrm{O}$. Adjust the $\mathrm{pH}$ to 7.2-7.4. This solution can be stored at $4{ }^{\circ} \mathrm{C}$ for 1 month.

2\% (vol/vol) osmium tetroxide Dissolve $25 \mathrm{ml}$ of $4 \%$ (vol/vol) osmium tetroxide in $25 \mathrm{ml}$ of $0.2 \mathrm{M}$ sodium cacodylate ( $\mathrm{vol} / \mathrm{vol}$ ). The solution should be left at RT in a fume hood for 1-2 d until all crystals have been dissolved, and then it can be stored at $4{ }^{\circ} \mathrm{C}$ for up to 6 months as long as the color is pale yellow.

Ethanol Use 35, 50, 70, 95 and 70\% ethanol in $\mathrm{ddH}_{2} \mathrm{O}$ and $100 \%$ ethanol.

Spurr's resin solution (reagents found in the low viscosity embedding kit) Mix $10 \mathrm{~g}$ of vinyl cyclohexene dioxide (ERL4221), $8 \mathrm{~g}$ of diglycidyl etherpolypropylene glycol (DER736), $25 \mathrm{~g}$ of nonenyl succinic anhydride and $0.3 \mathrm{~g}$ of dimethylamino ethanol. Freshly prepare the solution for each use.

Hoechst 33342, Trihydrochloridetrihydrochloride, Trihydrate The solution can be aliquotted and stored protected from light at $-20{ }^{\circ} \mathrm{C}$ for up to 1 year.

\section{EQUIPMENT SETUP}

Cleaning of instruments All instruments should be sterilized using a steam autoclave (30 min at $121{ }^{\circ} \mathrm{C}$ ). The dissecting microscope should be cleaned with $70 \%$ ethanol and placed inside a laminar flow hood to perform the whole process under sterile conditions.

\section{PROCEDURE}

\section{Preparation of Transwells $\bigcirc$ TIMING $\sim 1.5 \mathrm{~h}$}

1) Before RPE collection, equilibrate 6.5-mm Transwells in RPE medium ${ }^{25}{ }^{\circ} \mathrm{C}, 5 \%$ $\mathrm{CO}_{2}$. Remove the medium and add $700 \mu \mathrm{l}$ of PBS to the lower compartment and coat the top compartment insert with $100 \mu \mathrm{g} / \mathrm{ml}$ mouse laminin for at least $2 \mathrm{~h}$ at Rt. Coat an extra Transwell that will be used as a blank for TER measuremetns.

$\triangle$ CRITICAL STEP It is important to coat the Transwells with laminin for $2 \mathrm{~h}$ or more, as shorter incubations may lead to poor attachment of the cells to the insert. 


\section{Dissection of the eye TIMING $\sim 2.5-3 \mathrm{~h}$}

2| Euthanize mice by $\mathrm{CO}_{2}$ asphyxiation or decapitation (see Experimental design for details).

$\triangle$ CRITICAL STEP The guidelines of the ARVO Statement for the Use of Animals in Ophathalmic and Vision Research should be followed.

A CRITICAL STEP To prevent contamination, the skin and eyes of the mouse are briefly dipped in 70\% ethanol and placed into fresh HBSS-H- on ice until use. If decapitation was performed, dip the whole head in $70 \%$ ethanol before enucleation.

3| Using angled microforceps, position the serrated angled tips on each side of the eye and gently press so that the eyeball comes out.

4) Close the forceps and pull gently, moving forward and backward to detach the whole eye, with the optic nerve (to facilitate handling), from the ocular muscles.

$\triangle$ CRITICAL STEP Ensure that no connective tissue remains attached to the sclera at enucleation, to lower the probability of disturbing RPE cells during the procedure.

5| Immediately dip the eye in $70 \%$ ethanol and place it in a six-well plate containing $3 \mathrm{ml}$ of HBSS-H- on ice ( $3 \mathrm{ml}$ per two eyes).

$\triangle$ CRITICAL STEP To avoid cross-contamination, only eyes from mice with the same genotype should be processed at one time.

$\triangle$ CRITICAL STEP Do not collect more than two eyes at the same time. Extended incubation on ice will cause the neural retina to shrink and the RPE cells to die. Isolation of RPE cells should be performed as soon as possible after enucleation.

$\triangle$ CRITICAL STEP All procedures after the removal of eyes (from Step 4 onward) should be performed in a laminar flow hood under sterile conditions.

6| In a cell culture hood under sterile conditions, use a dissecting stereomicroscope to aid the use of Dumont \#5 tweezers and angled scissors to carefully clean away all the connective tissue and muscles without making any cuts in the sclera. Change the HBSS-H- buffer regularly to keep the eye fresh and clean.

$\triangle$ CRITICAL STEP Handle the scissors carefully so as to avoid tearing the sclera. If the sclera is cut, the neural retina will come out and the RPE sheets will be damaged. It is important that no connective tissue or blood remains, as this could eventually contaminate the RPE cultures.

\section{? TROUBLESHOOTING}

7| Use a sharp carbon-steel \#11 blade to hold the eye by the optic nerve with Dumont \#5 tweezers and to make a hole in the center of the cornea (Fig. 2a).

$\triangle$ CRITICAL STEP To ensure the integrity of the RPE sheets, it is important that the blade be sharp enough and used only once, so that minimum pressure is 
used to make the incision. It is key that the eye is not squeezed and that the lens is not pierced at this point.

8| Using the hole as the center, divide the cornea with three cuts using Dumont \#5 scissors so that there is enough room for the lens to come out (Fig. 2a,b).

9| Hold the optic nerve and apply a little pressure to the ora serrata with the base of the angled scissors until the lens comes completely out (Fig. 2b).

$\triangle$ CRITICAL STEP Minimum pressure should be applied. If the hole is too small, cut a little more. Otherwise, the eye could rupture and the neural retina will come out, damaging the RPE underneath.

\section{? TROUBLESHOOTING}

10| Place the first eye in fresh HBSS-H- buffer and repeat Steps 6-9 to dissect the second eye.

11 Once both lenses have been removed, place each eye in one well of a 12-well plate containing $1.5 \mathrm{ml}$ of hyaluronidase solution. Incubate the eyes at $37^{\circ} \mathrm{C}$, $5 \% \mathrm{CO}_{2}$ for $45 \mathrm{~min}$.

12 Transfer each eye to a new 12-well plate containing $1.5 \mathrm{ml}$ of ice-cold HBSS-H+ buffer per well, and incubate the eyes for $30 \mathrm{~min}$ on ice to stop the activity of the hyaluronidase.

$\triangle$ CRITICAL STEP After washing, some RPE cells may remain attached to the neural retina, especially if the mice were young. In this case, longer incubation in HBSS-H+ buffer on ice may help, but do not exceed 45 min, in order to avoid cell death.

13| Transfer each eye to a $35-\mathrm{mm}$ culture dish containing fresh HBSS-H+ buffer. Use 8-cm Vannas scissors to cut deeper along the original incisions on the cornea until reaching the ora serrata. Cut below the ora serrata to remove the iris epithelium and cornea (Fig. 3a).

14 Gently pull away the neural retina using angled microforceps and cut the internal attachment to the optic nerve (Fig. 3b-d).

$\triangle$ CRITICAL STEP Do not cut the RPE layer when pulling away the neural retina. Hold on to the eyecup by the edge/ora serrata using curved tweezers, so that the RPE cells are not damaged (Fig. 3b).

\section{? TROUBLESHOOTING}

15| Cut the optic nerve and transfer each eyecup to a 12-well plate containing $1.5 \mathrm{ml}$ of trypsin per well. Incubate the eyecups at $37^{\circ} \mathrm{C}, 5 \% \mathrm{CO}_{2}$ for $45 \mathrm{~min}$.

$\Delta$ crItIcal step Make sure that the eyecup remains open and completely submerged in the trypsin, so that the solution is in contact with all the RPE cells. Do not incubate two eyecups together in the same well or more than two eyes at the same time. Trypsin-EDTA should be aliquotted and frozen so that individual aliquots can be thawed at RT for each use; re-freezing is not recommended. 
16| Transfer each eyecup into a 12-well plate containing $1.5 \mathrm{ml}$ of FBS solution per well.

$\triangle$ CRITICAL STEP Sometimes RPE sheets detach during the incubation period and remain in the trypsin solution after removal of the eyecup. Collect them with a p200 pipette and add them to the FBS solution.

\section{Isolation of primary mouse RPE cells 0 TIMING $\sim 30$ min}

17| Place each eyecup face down and hold it by the external attachment of the optic nerve. Gently shake it vertically into the 12 -well plate containing $1.5 \mathrm{ml}$ of $20 \%$ FBS in HBSS-H+ until all the RPE sheets are detached (Fig. 4a-c). After all RPE cells are detached, the choroid should be intact in the eyecup (Fig. 4d). Only RPE sheets and RPE clusters should be collected; any white piece of sclera or choroid fragments should be avoided. RPE sheet size may vary among samples, but in general they range from groups of four or five cells to large sheets of a few millimeters (Fig. 4c).

A CRITICAL STEP Do not blow on the buffer or use any mechanical method to detach the RPE sheets from the eyecup; they will come out easily with shaking alone.

\section{? TROUBLESHOOTING}

18| Collect the RPE sheets with a p200 micropipette and place them in a 15-ml tube. Pool two eyes from the same mouse in one tube.

$\triangle$ CRITICAL STEP Do not make any bubbles that could disturb the RPE sheets. Do not collect any pieces of sclera or choroid, which could contaminate the cultures. Change pipette tips often, especially if pieces of sclera or choroid are aspirated.

$\triangle$ CRITICAL STEP Cells might lose viability if left in suspension for a long time. If more than two eyes were collected at the same time, shift the incubation times to optimize timing and ensure that no more than two eyes reach this step at the same time.

19| Centrifuge the mixture at $340 \mathrm{~g}$ for $2 \mathrm{~min}$ at RT. Discard the supernatant.

20| Carefully resuspend the RPE pellet in $1 \mathrm{ml}$ of $0.05 \%$ trypsin $+0.02 \%$ EDTA. Incubate the mixture for $1 \mathrm{~min}$ in a water bath at $37^{\circ} \mathrm{C}$.

$\triangle$ CRITICAL STEP At this stage, the cells are very fragile. Pipetting should be gentle. Avoid bubble formation.

$\triangle$ CRITICAL STEP Disaggregation of the RPE sheets is necessary for creation of a single-cell suspension. Large RPE sheets will roll and wrap in culture, and the cells will not attach properly.

21 Gently add $9 \mathrm{ml}$ of freshly prepared RPE medium at RT. Centrifuge the mixture at $340 \mathrm{~g}$ for $2 \mathrm{~min}$ at RT and discard the supernatant. 
$\triangle$ CRITICAL STEP It is necessary to add $9 \mathrm{ml}$ of RPE medium so that trypsin is diluted ten times and the reaction is stopped. The cell pellet will be left with some microliters of medium after centrifugation, so it is key that the trypsin is well diluted.

22 Remove the supernatant with a Pasteur pipette and add $150 \mu \mathrm{l}$ of RPE medium containing 5\% FBS. Gently pipette the RPE cells up and down, up to ten times, with a p200 micropipette. This will be sufficient to ensure that they are homogeneously resuspended.

$\triangle$ CRITICAL STEP This step is necessary for the RPE cells to distribute evenly in the culture. Do not make bubbles.

23| Take pre-prepared Transwell chambers (as described in Equipment Setup) and replace PBS from the bottom chamber of the Transwell with $700 \mu$ of RPE medium.

24| Aspirate $100 \mu \mathrm{l}$ of laminin from the upper chamber of the Transwell and add the RPE suspension drop-wise to the center of the insert. Check under a microscope that the cells are evenly distributed.

A CRITICAL STEP Avoid any bubbles. Bubbles will make the cells distribute unevenly.

25| Place the Transwells in an incubator at $37{ }^{\circ} \mathrm{C}, 5 \% \mathrm{CO}_{2}$.

\section{Generation of polarized RPE monolayers TIMING $72 \mathrm{~h}$ to several weeks}

26| Culture the cells for at least $72 \mathrm{~h}$ before changing the medium. Most of the cells will be attached to the Transwell after $24 \mathrm{~h}$.

\section{? TROUBLESHOOTING}

27| Change the culture medium twice a week. After the first $72 \mathrm{~h}$, serum can be removed from the medium. After 1 week, cells should be confluent, hexagonal, bi-nucleated, pigmented and polarized (Fig. 1a,b). Proceed to measurement of TER (Step 28) after $4 \mathrm{~d}$ in culture. We have maintained cells in culture as long as 3 months.

\section{? TROUBLESHOOTING}

\section{Measuring ter $\bigcirc$ TIMING 3 min}

28 TER can be measured after a minimum of $4 \mathrm{~d}$ in culture. Rinse the electrodes of the voltohmmeter with 70\% ethanol. $\triangle$ CRITICAL STEP Measurements should be performed within 3 min after the Transwells are taken from the incubator, as temperature fluctuations affect TER measurement 47 .

A CRITICAL STEP The short electrode should be immersed in the upper compartment and the long electrode should be immersed in the bottom compartment, as previously described26. Electrodes should never touch the RPE monolayer; otherwise, the cells will detach from the insert. 
29| Calculate TER by subtracting the value obtained in the blank (Transwell coated with laminin without cells) from the sample. Multiply this value (in ohms) by the surface area of the Transwell $(0.33 \mathrm{~cm} 2$ in the case of $6.5-\mathrm{mm}$ Transwells). The value should be at least $100 \Omega \cdot \mathrm{cm}^{2}$ after $72 \mathrm{~h}$ in culture.

30| Return the cells to the incubator if you wish to continue to culture.

\section{Characterization of the RPE monolayers TIMING 1.5-3 d}

31 To characterize RPE monolayers by immunostaining of the tight-junction protein ZO-1, follow option A; to characterize RPE cultures by TEM, follow option B; and to characterize RPE cultures by SEM, follow option C. Depending on the mouse model of interest, other proteins can be used to characterize the RPE cultures. Intracellular proteins are better visualized in transverse sections of the Transwells, which are made using a vibratome (see Box 1 and Figs. 5 and 6 for details of this procedure.

\section{(A) Immunostaining of the tight-junction protein Zo-1 0 TIMING $1.5 \mathrm{~d}$}

i. Fix the RPE cells on Transwells with 4\% (vol/vol) PFA in PBS for 10 min at RT. Next, rinse with PBS and fix the cells with $1 \%$ (vol/vol) glutaraldehyde in PBS for $30 \mathrm{~min}$ at RT. Add $700 \mu \mathrm{l}$ of the solution to the bottom and $150 \mu \mathrm{l}$ to the top chamber.

- PAUSE POINT Once fixed, the samples can be stored in sterile PBS at $4{ }^{\circ} \mathrm{C}$ for several months.

ii. Remove the insert from the Transwell with a sterile \#11 carbon blade. After fixation, inserts can be cut into smaller pieces to be incubated with different antibodies.

iii. Place the insert in a 24-well plate containing $500 \mu \mathrm{l}$ of PBS.

iv. Rinse the insert with PBS at RT and block it in 1\% (wt/vol) BSA in PBS for 45 min at RT.

v. Incubate with rabbit anti-mouse ZO-1 primary antibody diluted $1 / 100$ (vol/vol) in $1 \%(\mathrm{wt} / \mathrm{vol}) \mathrm{BSA}$ in PBS at $4{ }^{\circ} \mathrm{C}$ overnight in a humidity chamber. Add enough volume of antibody to cover the total surface of the insert.

vi. Remove the primary antibody and wash it three times with PBS for 5 min at RT. Use enough volume of PBS to cover the total surface of the insert.

vii. Incubate with anti-rabbit fluorescein-conjugated secondary antibody diluted $1 / 1,000(\mathrm{vol} / \mathrm{vol})$ in $1 \%(\mathrm{wt} / \mathrm{vol}) \mathrm{BSA}$ in PBS for $1 \mathrm{~h}$ at RT in the dark.

viii. Remove the secondary antibody and wash the inserts three times with PBS.

ix. Incubate the insert for $5 \mathrm{~min}$ with Hoechst dye $(1 \mu \mathrm{g} / \mathrm{ml})$ for nuclei staining. Add the same volume used for antibody incubation.

x. Carefully place the insert on a glass slide cell-side up. 
xi. Wash with PBS and mount by pipetting a drop of Fluoromount $\mathrm{G}$ mounting medium onto the insert. Place the coverslip and press it down to leave it as flat as possible. View the slide using a confocal microscope.

\section{(B) Characterization of RPE cultures by TEM - TIMING $3 \mathrm{~d}$}

i. Add $700 \mu \mathrm{l}$ of half-strength Karnovsky's fixative to the bottom Transwell chamber and $150 \mu \mathrm{l}$ to the top chamber to fix RPE cells at RT for a minimum of $12 \mathrm{~h}$.

ii. Rinse RPE cells twice with $0.1 \mathrm{M}$ sodium cacodylate buffer.

- PAUSE POINT Samples can be stored in $0.1 \mathrm{M}$ sodium cacodylate buffer at $4{ }^{\circ} \mathrm{C}$ for 2 weeks.

iii. Use a sharp carbon \#11 surgical blade to remove the insert from the Transwell and place it in a 12-well plate.

iv. Postfix the cells with $500 \mu \mathrm{l}$ of $2 \%$ (vol/vol) osmium tetroxide in $0.1 \mathrm{M}$ cacodylate buffer, $\mathrm{pH} 7.2-7.4$, for $1.5 \mathrm{~h}$ at $4{ }^{\circ} \mathrm{C}$. (v) Rinse the cells twice with $500 \mu \mathrm{l}$ of $0.1 \mathrm{M}$ cacodylate buffer.

v. Rinse the cells twice with $500 \mu \mathrm{l}$ of $\mathrm{dH}_{2} \mathrm{O}$.

vi. Stain the cells with $500 \mu \mathrm{l}$ of $2 \%$ uranyl acetate in $\mathrm{dH}_{2} \mathrm{O}$ for 30 min and rinse with $\mathrm{dH}_{2} \mathrm{O}$.

vii. Dehydrate through a graded series of ethanol: $35 \%$ for $15 \mathrm{~min}, 50 \%$ for $15 \mathrm{~min}$, $70 \%$ for $15 \mathrm{~min}$, twice in $95 \%$ for $15 \mathrm{~min}$, twice in $100 \%$ for $15 \mathrm{~min}$ and $100 \%$ for $1 \mathrm{~h}$.

viii. Infiltrate with graded Spurr's resin hard formulation (ethanol/Spurr's resin: 70/30, 50/50 and 30/70 for 3, 10 and $3 \mathrm{~h}$, respectively) followed by $100 \%$ Spurr's resin overnight.

ix. Embed in $100 \%$ Spurr's resin and leave under vacuum at $60{ }^{\circ} \mathrm{C}$ for $24 \mathrm{~h}$.

Cut sections at a thickness of $1 \mu \mathrm{m}$ using an ultramicrotome and stain them with $1 \%$ toluidine blue in $1 \%$ sodium tetraborate aqueous solution for examination with a light microscope.

A CRITICAL STEP Before preparing TEM grids, it is recommended to image thin sections to ensure that the RPE monolayer did not detach from the insert during fixation/embedding. If the cells detach from the Transwells during the process, basal infoldings can lose their morphology.

x. Cut ultrathin sections at a thickness of 100-200 $\mathrm{nm}$ using an ultramicrotome and collect them onto uncoated grids for TEM.

xi. Image sections using an FEI Tecnai G2 Spirit TEM or other suitable instrument. 


\section{(C) Characterization of RPE cultures by SEM - TIMING $2 \mathrm{~d}$}

i. Fix the RPE cells on Transwells with $4 \%$ (vol/vol) PFA for $10 \mathrm{~min}$ at RT. Next, rinse the cells with PBS and fix them with $1 \%$ (vol/vol) glutaraldehyde for 30 min at RT. Add $700 \mu \mathrm{l}$ of the solution to the bottom and $150 \mu \mathrm{l}$ to the top chamber.

ii. Remove the insert from the Transwell with a sterile \#11 carbon blade.

iii. Rinse inserts with $\mathrm{dH}_{2} \mathrm{O}$ and dehydrate them by immersion in a series of ethanol baths: $35 \%, 50 \%, 70 \%, 95 \%$ and $95 \%$ (20 min each), and 100\% (twice for 30 min each time).

- PAUSE POINT Samples can be left in $100 \%$ ethanol overnight.

iv. Dry samples for 10 min using a critical point dryer system such as the SAMDRI-795 system. Dehydration can be also performed by air-drying samples; however, replacing the water in biological tissue with $\mathrm{CO}_{2}$ helps to preserve sample morphology.

v. Split dehydrated inserts in half and flip one of them so that the apical and distal surfaces can be imaged.

- PAUSE POINT Samples can be covered and left at RT in a dry place for several days.

vi. Coat the apical and distal sides with chromium on a sputter coater for $10 \mathrm{~min}$.

- PAUSE POINT Samples can be covered and stored at RT in a dry place for several months.

vii. Image coated inserts with an SEM such as a JEOL $7401 \mathrm{~F}$ (filament voltage at 5 $\mathrm{kV})$.

\section{? TROUBLESHOOTING}

Troubleshooting advice can be found in Table 1.

- TIMING

Step 1, preparation of Transwells: $\sim 1.5 \mathrm{~h}$

Steps $2-16$, dissection of the eye: $\sim 2.5-3 \mathrm{~h}$

Steps $17-25$, isolation of primary mouse RPE cells: $\sim 30 \mathrm{~min}$

Steps 26 and 27, generation of polarized RPE monolayers: $72 \mathrm{~h}$ to several weeks

Steps 28-30, measuring TER: 3 min

Step 31, characterization of the RPE monolayers: $1.5-3 \mathrm{~d}$

Step 31A, immunostaining of the tight-junction protein ZO-1: $1.5 \mathrm{~d}$ 
Step 31B, characterization of RPE cultures by TEM: $3 \mathrm{~d}$

Step 31C, characterization of RPE cultures by SEM: $2 \mathrm{~d}$

Box 1, vibratome sectioning to visualize transverse sections of the Transwells: $1 \mathrm{~d}$

\section{ANTICIPATED RESULTS}

Our primary mouse RPE cultures usually stabilize in $\sim 3-4 \mathrm{~d}$ in culture. After this period, the percentage of cell death will be $<20 \%$. During the first $24 \mathrm{~h}$, cells are variable in terms of size, morphology and pigmentation, and they appear as rounded cells with no nuclei or only a single nucleus visible (Fig. 1a). The morphology and size change as they start spreading toward the surrounding cells on the Transwell to form the honeycomb, where most cells are bi-nucleated (Fig. 1b). We consider a culture to be of good quality when it exhibits a honeycomb morphology in $\sim 80 \%$ of the cells, when the overall pigmentation is homogeneous and when it has a TER $>100 \Omega \bullet \mathrm{cm}^{2}$ (Fig. 1b).

RPE cultures with low TER or abnormal morphology (Fig. 1c,d) should be discarded. In our experience, although the RPE cells may appear normal after isolation, if the attachment takes longer than $24 \mathrm{~h}$, the cells will exhibit dark pigmentation and a larger size. This happens very rarely, and we think that it is because of insufficient coating of the Transwell. For instance, it may happen if the time of incubation of the insert with laminin is $<2 \mathrm{~h}$

Contamination with other cell types is not expected, but it can be ruled out by measuring the expression of markers for other cell types by qRT-PCR ${ }^{12}$.

In vivo, RPE cells grow as a polarized monolayer and secrete different substances on their apical and basal surfaces ${ }^{43,48,49}$. In culture, RPE cells grown on permeable supports reach polarization and secrete molecules from apical and basolateral surfaces to the upper and lower culture compartments, respectively. Differentiated apical and basal secretion recapitulates in vivo cellular mechanisms in vitro and creates a physiological environment within 1 week $^{12,21,25,26,43,50}$. To test polarization, differential apical and basal secretion of substances such as cytokines can be measured in media supernatants12.

To reproduce the physiology of healthy RPE, monolayers should exhibit strong barrier properties and low permeability, as indicated by a high TER and the expression of tightjunction-specific proteins such as ZO-1, occludin and claudins ${ }^{2,14,51}$. In our RPE cultures, ZO-1 is expressed uniformly after 1 week (Fig. 7a).

The morphology of the polarized RPE monolayer is also visible by TEM, with which tight junctions, apical microvilli, basal infoldings and melanin pigment are clearly observable (Fig. 7b). The correct formation of the RPE monolayer can be also examined by SEM, with which the typical honeycomb structure, as well as apical microvilli, can be visualized (Fig. $7 \mathrm{c}, \mathrm{d})$.

Whenever the RPE barrier is compromised, it will be reflected in TER values. TER of the RPE cultures is measured using an epithelial tissue voltohmmeter (EVOM); after $3 \mathrm{~d}$ in culture, TER should be $>200 \Omega \cdot \mathrm{cm}^{2}$, and it should reach $>400 \Omega \cdot \mathrm{cm}^{2}$ after 2 weeks (Fig. 
8). The analysis of proteins expressed in the cytoplasm of the RPE cells can be also done by immunos-taining vibratome sections of the RPE on transwells (Fig. 6).

\section{ACKNOWLEDGMENTS}

This work was supported by the Ocular Genomics Institute. The TEM work was supported in part by the National Eye Institute Core (grant P30EY003790). We would like to thank Schepens Eye Research Institute Morphology Core Facility for performing the TEM, A. Tisdale for helpful technical assistance with SEM and A. Langsdorf for helpful comments that improved the manuscript.

\section{References}

1. Strauss O The retinal pigment epithelium in visual function. Physiol. Rev 85, 845-881 (2005). [PubMed: 15987797]

2. Konari $\mathrm{K}$ et al. Development of the blood-retinal barrier in vitro: formation of tight junctions as revealed by occludin and ZO-1 correlates with the barrier function of chick retinal pigment epithelial cells. Exp. Eye Res 61, 99-108 (1995). [PubMed: 7556475]

3. Kay P, Yang YC \& Paraoan L Directional protein secretion by the retinal pigment epithelium: roles in retinal health and the development of age-related macular degeneration. J. Cell. Mol. Med 17, 833-843 (2013). [PubMed: 23663427]

4. Anderson JM \& Van Itallie CM Tight junctions and the molecular basis for regulation of paracellular permeability. Am. J. Physiol 269, G467-G475 (1995). [PubMed: 7485497]

5. Holtkamp GM, Kijlstra A, Peek R \& de Vos AF Retinal pigment epithelium-immune system interactions: cytokine production and cytokine-induced changes. Prog. Retin. Eye Res 20, 29-48 (2001). [PubMed: 11070367]

6. Taylor AW Ocular immune privilege. Eye (Lond) 23, 1885-1889 (2009). [PubMed: 19136922]

7. Johnson LV, Leitner WP, Staples MK \& Anderson DH Complement activation and inflammatory processes in Drusen formation and age related macular degeneration. Exp. Eye Res 73, 887-896 (2001). [PubMed: 11846519]

8. Hageman GS et al. An integrated hypothesis that considers drusen as biomarkers of immunemediated processes at the RPE-Bruch's membrane interface in aging and age-related macular degeneration. Prog. Retin. Eye Res 20, 705-732 (2001). [PubMed: 11587915]

9. Kijlstra A, La Heij E \& Hendrikse F Immunological factors in the pathogenesis and treatment of age-related macular degeneration. Ocul. Immunol. Inflamm 13, 3-11 (2005). [PubMed: 15804763]

10. Lommatzsch A et al. Are low inflammatory reactions involved in exudative age-related macular degeneration? Morphological and immunhistochemical analysis of AMD associated with basal deposits. Graefes Arch. Clin. Exp. Ophthalmol 246, 803-810 (2008). [PubMed: 18414889]

11. Bandyopadhyay M \& Rohrer B Matrix metalloproteinase activity creates pro-angiogenic environment in primary human retinal pigment epithelial cells exposed to complement. Invest. Ophthalmol. Vis. Sci 53, 1953-1961 (2012). [PubMed: 22408008]

12. Fernandez-Godino R, Garland DL \& Pierce EA A local complement response by RPE causes early-stage macular degeneration. Hum. Mol. Genet 24, 5555-5569 (2015). [PubMed: 26199322]

13. Farkas MH et al. Mutations in pre-mRNA processing factors 3, 8, and 31 cause dysfunction of the retinal pigment epithelium. Am. J. Pathol 184, 2641-2652 (2014). [PubMed: 25111227]

14. Geisen P, McColm JR, King BM \& Hartnett ME Characterization of barrier properties and inducible VEGF expression of several types of retinal pigment epithelium in medium-term culture. Curr. Eye Res 31, 739-748 (2006). [PubMed: 16966147]

15. Schutze $C$ et al. Retinal pigment epithelium findings in patients with albinism using wide-field polarization-sensitive optical coherence tomography. Retina 34, 2208-2217 (2014). [PubMed: 25046395]

16. Samuels IS, Bell BA, Pereira A, Saxon J \& Peachey NS Early retinal pigment epithelium dysfunction is concomitant with hyperglycemia in mouse models of type 1 and type 2 diabetes. J. Neurophysiol 113, 1085-1099 (2015). [PubMed: 25429122] 
17. Sparrow JR, Hicks D \& Hamel CP The retinal pigment epithelium in health and disease. Curr. Mol. Med 10, 802-823 (2010). [PubMed: 21091424]

18. Curcio CA \& Johnson M Structure, function, and pathology of Bruch's membrane. Retina 1, 465481 (2013).

19. Wang L et al. Abundant lipid and protein components of drusen. PLoS One 5, e10329 (2010). [PubMed: 20428236]

20. Fernandez-Godino R, Pierce EA \& Garland DL Extracellular matrix alterations and deposit formation in AMD. Adv. Exp. Med. Biol 854, 53-58 (2016). [PubMed: 26427393]

21. Dunn KC, Aotaki-Keen AE, Putkey FR \& Hjelmeland LM ARPE-19, a human retinal pigment epithelial cell line with differentiated properties. Exp. Eye Res 62, 155-169 (1996). [PubMed: 8698076]

22. Flannery JG Transgenic animal models for the study of inherited retinal dystrophies. ILAR J. 40, 51-58 (1999). [PubMed: 11533514]

23. Gibbs D \& Williams DS Isolation and culture of primary mouse retinal pigmented epithelial cells. Adv. Exp. Med. Biol 533, 347-352 (2003). [PubMed: 15180284]

24. Mayerson PL, Hall MO, Clark V \& Abrams T An improved method for isolation and culture of rat retinal pigment epithelial cells. Invest. Ophthalmol. Vis. Sci 26, 1599-1609 (1985). [PubMed: 4055292]

25. Maminishkis A et al. Confluent monolayers of cultured human fetal retinal pigment epithelium exhibit morphology and physiology of native tissue. Invest. Ophthalmol. Vis. Sci 47, 3612-3624 (2006). [PubMed: 16877436]

26. Sonoda $\mathrm{S}$ et al. A protocol for the culture and differentiation of highly polarized human retinal pigment epithelial cells. Nat. Protoc 4, 662-673 (2009). [PubMed: 19373231]

27. Wang N, Koutz CA \& Anderson RE A method for the isolation of retinal pigment epithelial cells from adult rats. Invest. Ophthalmol. Vis. Sci 34, 101-107 (1993). [PubMed: 8425817]

28. Bonilha VL, Finnemann SC \& Rodriguez-Boulan E Ezrin promotes morphogenesis of apical microvilli and basal infoldings in retinal pigment epithelium. J. Cell Biol 147, 1533-1548 (1999). [PubMed: 10613910]

29. Nandrot EF et al. Loss of synchronized retinal phagocytosis and age-related blindness in mice lacking alphavbeta5 integrin. J. Exp. Med 200, 1539-1545 (2004). [PubMed: 15596525]

30. Chen $\mathrm{M}$ et al. Characterization of a spontaneous mouse retinal pigment epithelial cell line B6RPE07. Invest. Ophthalmol. Vis. Sci 49, 3699-3706 (2008). [PubMed: 18421091]

31. Blenkinsop TA, Salero E, Stern JH \& Temple $S$ The culture and maintenance of functional retinal pigment epithelial monolayers from adult human eye. Methods Mol. Biol 945, 45-65 (2013). [PubMed: 23097100]

32. Garland DL et al. Mouse genetics and proteomic analyses demonstrate a critical role for complement in a model of DHRD/ML, an inherited macular degeneration. Hum. Mol. Genet 23, 52-68 (2014). [PubMed: 23943789]

33. Fu L et al. The R345W mutation in EFEMP1 is pathogenic and causes AMD-like deposits in mice. Hum. Mol. Genet 16, 2411-2422 (2007). [PubMed: 17666404]

34. Zeiss CJ Animals as models of age-related macular degeneration: an imperfect measure of the truth. Vet. Pathol 47, 396-413 (2010). [PubMed: 20382825]

35. Weng $\mathrm{J}$ et al. Insights into the function of Rim protein in photoreceptors and etiology of Stargardt's disease from the phenotype in abcr knockout mice. Cell 98, 13-23 (1999). [PubMed: 10412977]

36. Maiti $P$ et al. Small molecule RPE65 antagonists limit the visual cycle and prevent lipofuscin formation. Biochemistry 45, 852-860 (2006). [PubMed: 16411761]

37. Ran FA et al. Double nicking by RNA-guided CRISPR Cas9 for enhanced genome editing specificity. Cell 154, 1380-1389 (2013). [PubMed: 23992846]

38. Wang S, Sengel C, Emerson MM \& Cepko CL A gene regulatory network controls the binary fate decision of rod and bipolar cells in the vertebrate retina. Dev. Cell 30, 513-527 (2014). [PubMed: 25155555] 
39. Gibbs D, Kitamoto J \& Williams DS Abnormal phagocytosis by retinal pigmented epithelium that lacks myosin VIIa, the Usher syndrome 1B protein. Proc. Natl. Acad. Sci. USA 100, 6481-6486 (2003). [PubMed: 12743369]

40. Liu Y et al. Zeb1 represses Mitf and regulates pigment synthesis, cell proliferation, and epithelial morphology. Invest. Ophthalmol. Vis. Sci 50, 5080-5088 (2009). [PubMed: 19515996]

41. Stevenson BR, Siliciano JD, Mooseker MS \& Goodenough DA Identification of ZO-1: a high molecular weight polypeptide associated with the tight junction (zonula occludens) in a variety of epithelia. J. Cell Biol 103, 755-766 (1986). [PubMed: 3528172]

42. Van Itallie CM, Fanning AS, Bridges A \& Anderson JM ZO-1 stabilizes the tight junction solute barrier through coupling to the perijunctional cytoskeleton. Mol. Biol. Cell 20, 3930-3940 (2009). [PubMed: 19605556]

43. Hu J \& Bok D A cell culture medium that supports the differentiation of human retinal pigment epithelium into functionally polarized monolayers. Mol. Vis 7, 14-19 (2001). [PubMed: 11182021]

44. Anderson JM \& Van Itallie CM Physiology and function of the tight junction. Cold Spring Harb. Perspect. Biol 1, a002584 (2009). [PubMed: 20066090]

45. Gong J, Sagiv O, Cai H, Tsang SH \& Del Priore LV Effects of extracellular matrix and neighboring cells on induction of human embryonic stem cells into retinal or retinal pigment epithelial progenitors. Exp. Eye Res 86, 957-965 (2008). [PubMed: 18472095]

46. Kilkenny C, Browne WJ, Cuthill IC, Emerson M \& Altman DG Improving bioscience research reporting: the ARRIVE guidelines for reporting animal research. PLoS Biol. 8, e1000412 (2010). [PubMed: 20613859]

47. Kannan R et al. Stimulation of apical and basolateral VEGF-A and VEGF-C secretion by oxidative stress in polarized retinal pigment epithelial cells. Mol. Vis 12, 1649-1659 (2006). [PubMed: 17200665]

48. An E et al. Secreted proteome profiling in human RPE cell cultures derived from donors with age related macular degeneration and age matched healthy donors. J. Proteome Res 5, 2599-2610 (2006). [PubMed: 17022631]

49. Zhu D et al. Polarized secretion of PEDF from human embryonic stem cell-derived RPE promotes retinal progenitor cell survival. Invest. Ophthalmol. Vis. Sci 52, 1573-1585 (2011). [PubMed: 21087957]

50. Holtkamp GM et al. Polarized secretion of IL- 6 and IL-8 by human retinal pigment epithelial cells. Clin. Exp. Immunol 112, 34-43 (1998). [PubMed: 9566787]

51. Sawada N et al. Tight junctions and human diseases. Med. Electron Microsc 36, 147-156 (2003). [PubMed: 14505058] 


\section{Box 1 |}

\section{Vibratome sectioning to visualize transverse sections of the Transwells TIMING $1 \mathrm{~d}$}

\section{Additional materials}

- $\quad$ Leica VT1000S Vibratome (Leica)

- $\quad$ Humidity chamber tray (Sigma-Aldrich, cat. no. Z670146)

- $\quad$ Standard cryomold (VWR, cat. no. 4557)

- $\quad$ 0-ml conical tube (Corning, cat. no. 352070)

- $\quad$ 100-ml beaker (for example, VWR cat. no. 10754-948)

\section{Procedure}

1. Fix the RPE cells on Transwells with $4 \%$ (vol/vol) PFA in PBS for $10 \mathrm{~min}$ at RT. Next, rinse them with PBS and fix them with $1 \%$ (vol/vol) glutaraldehyde in PBS for 30 min at RT.

2. Split the insert with a razor blade into small fragments of $2.5 \times 5 \mathrm{~mm}$. A rectangular-shaped slice is recommended for ease of sectioning.

3. In a 50-ml conical tube, prepare $10 \%$ agarose type XI by dissolving $2.5 \mathrm{~g}$ of agarose in $25 \mathrm{ml}$ of PBS. Stir and place it inside a 100-ml beaker full of water.

4. Microwave until the agarose is dissolved, and then place the beaker with the tube in a large water bath set to $50{ }^{\circ} \mathrm{C}$ until the agarose temperature reaches exactly $45^{\circ} \mathrm{C}$ (for a precise measurement, the thermometer should be placed directly in the agarose solution).

5. Pour $1 \mathrm{ml}$ of agarose into a cryomold and immediately place a piece of Transwell into the mold, keeping it vertical, with the short side toward the bottom of the mold but not touching it. Leave it in a humidity chamber until the agarose polymerizes and the insert does not move. Leaving the block overnight at $4{ }^{\circ} \mathrm{C}$ works best. Blocks can be stored in a humidity chamber at $4{ }^{\circ} \mathrm{C}$ for up to 1 month.

$\triangle$ CRITICAL STEP Be careful to follow temperature recommendations. If the agarose is too hot, it will destroy the sample, and if it is too cold, it will not embed the insert properly and this will come out at cutting.

6. Cut $100-\mu \mathrm{m}$ sections at medium speed $(\sim 5)$ and amplitude $(\sim 6)$ in a vibratome. Sections should be sliced from the side of the insert without cells to the side of the cells, so cellular material is not dragged into the membrane (Fig. 5).

$\triangle$ CRITICAL STEP During sectioning, Transwell pieces may detach from the agarose without coming out completely. Before using the sections for immunostaining, visualize them under a microscope to ensure that the RPE layer is in place and intact. 


\section{? TROUBLESHOOTING}

7. Place the section on a glass slide for staining (see Step 31A and Figs. 5,6).

$\triangle$ PAUSE POINT Sections can be stored at $4{ }^{\circ} \mathrm{C}$ in a humidity chamber for several months. 


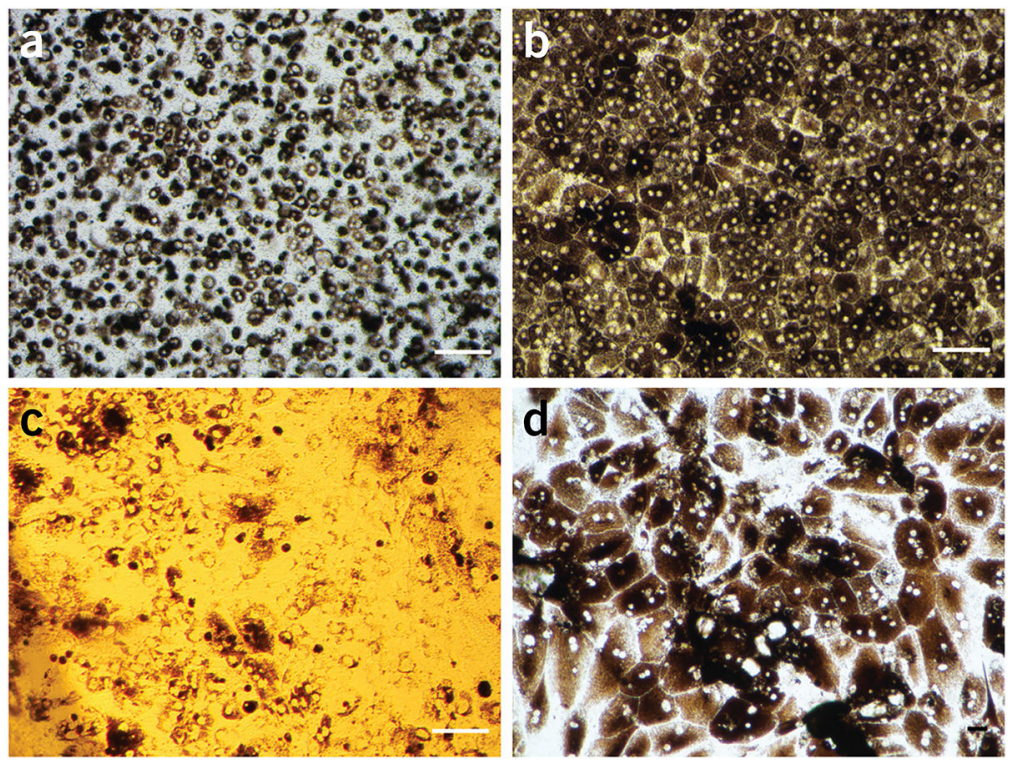

Figure 1 .

Morphology of the primary mouse RPE cultured on Transwells. (a) Primary RPE cells of a C57BL/6J female mouse aged 3 months old after $24 \mathrm{~h}$ on Transwells show high confluence and pigmentation. (b) RPE cells isolated from a 2-month-old C57BL/6J male mouse resulted in a primary RPE monolayer composed of hexagonal, bi-nucleated and pigmented RPE cells after 2 weeks in culture. (c) RPE cells isolated from a 2.5-month-old C57BL/6J male mouse. Bright-field microscopy showed low confluence of primary mouse RPE cultures with hypopigmentation and loss of shape after 1 week. (d) Bright-field microscopy image showing hyperpigmented and oversized RPE cells of two 2.5-month-old C57BL/10Sn female mice pooled on a 12-mm Transwell after 2 weeks in culture. Scale bars, $25 \mu \mathrm{m}$. 

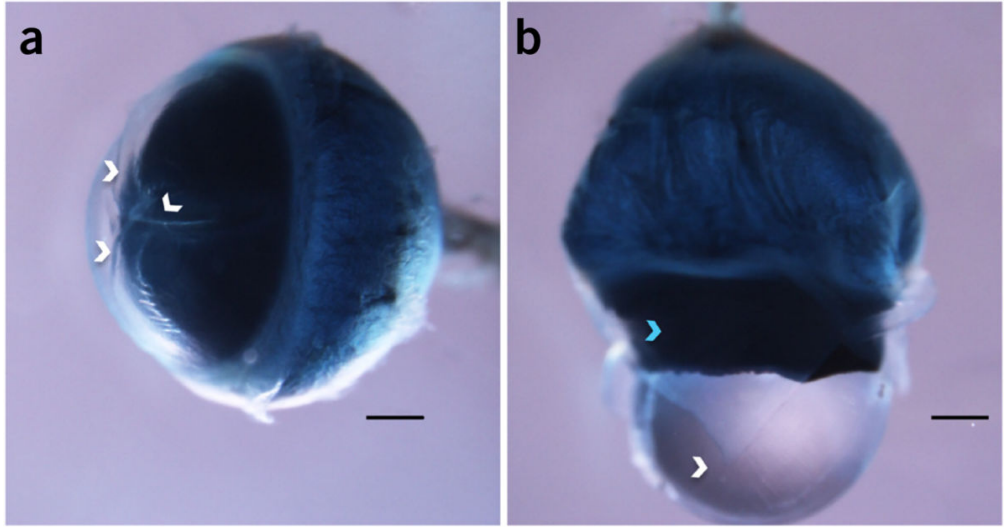

\section{Figure $2 \mid$.}

Dissection of the anterior portion of the eye of a wild-type male C57BL/6J mouse aged 2 months old. (a) The mouse eye was cleaned using angled microforceps and scissors, and three incisions were made across the cornea (white arrowheads) with a sterile \#11 carbon blade. The eyeball looks turgid, as no pressure was applied and the lens is still inside. (b) A little pressure was applied to the ora serrata with the base of the angled scissors until the lens (white arrowhead) came completely out of the eye without disturbing the iris epithelium (blue arrowhead). Scale bars, $1 \mathrm{~mm}$. The use of mice in this study was approved by the Massachusetts Eye and Ear Infirmary Animal Care and Use Committee and followed the ARRIVE guidelines ${ }^{46}$. 

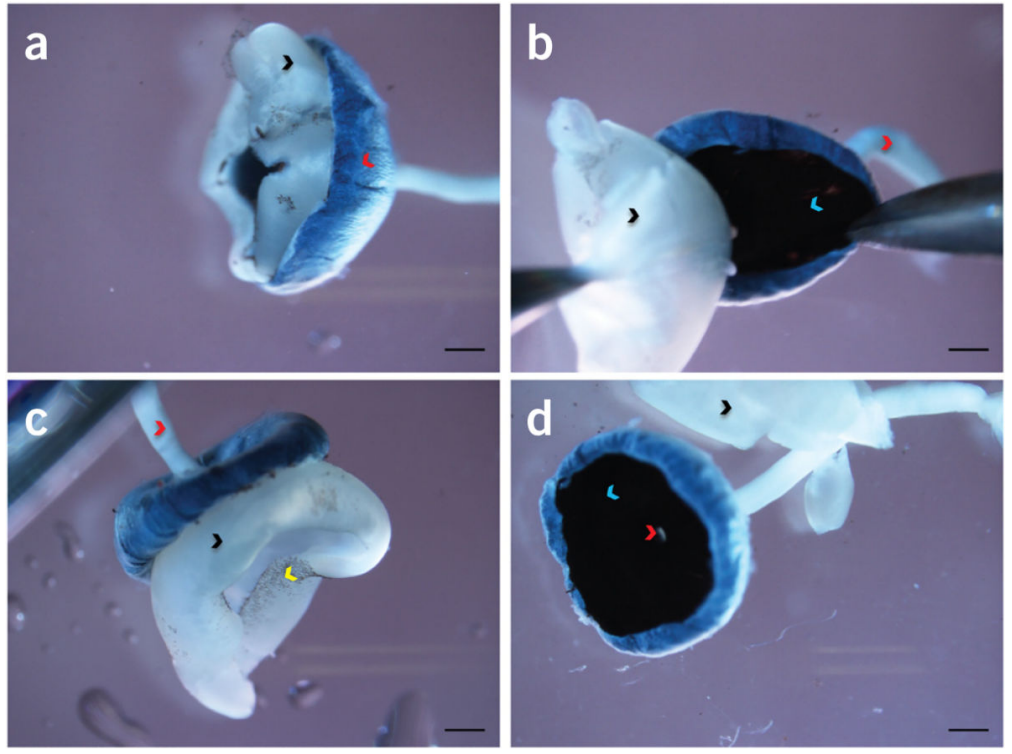

Figure 3 |.

Sequential dissection of neural retina of a wild-type male C57BL/6J mouse aged 2 months old. (a) Eyecup made with Vannas scissors after digestion with hyaluronidase and incubation on ice. Neural retina (black arrowhead) is separated from the eyecup (red arrowhead). (b,c) With the eyecup held by the optic nerve (red arrowhead), the neural retina (black arrowhead) can be pulled away with the angled microforceps without disturbing the RPE layer (blue arrowhead) (b). It is expected that some RPE cells (yellow arrowhead) will remain attached to the neural retina (c). (d) The neural retina (black arrowhead) is cut from the internal attachment to the optic nerve (red arrowhead) with angled scissors while the RPE layer (blue arrowhead) remains intact inside the eyecup. Scale bars, $1 \mathrm{~mm}$. The use of mice in this study was approved by the Massachusetts Eye and Ear Infirmary Animal Care and Use Committee and followed the ARRIVE guidelines ${ }^{46}$. 

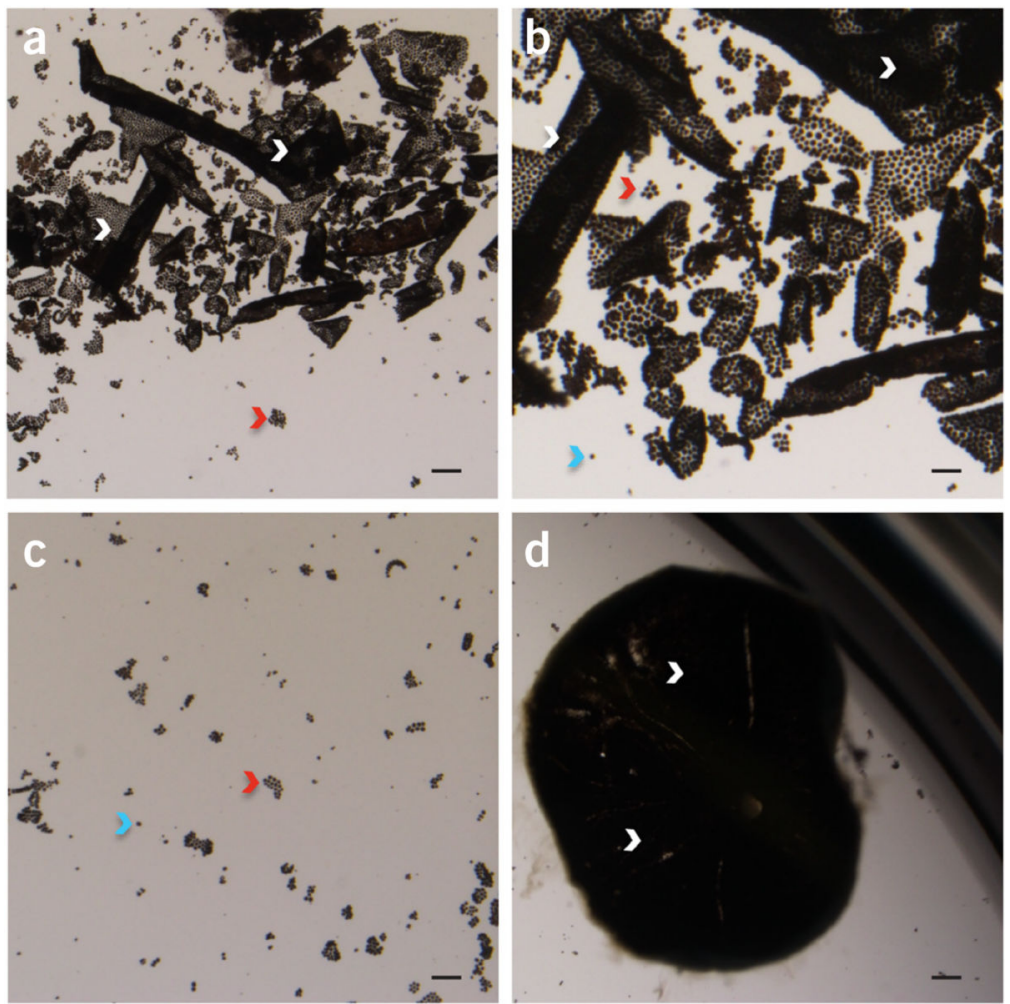

Figure 4 .

Collection of the RPE sheets of a wild-type female C57BL/6J mouse aged 3 months old. (ac) RPE sheets (white arrowheads), small clusters of RPE cells (red arrowheads) and single RPE cells (blue arrowheads) will detach from the eyecup upon shaking after incubation with trypsin. (d) After all RPE cells have been collected, choroid (white arrowhead) must remain intact inside the eyecup. Scale bars, $500 \mu \mathrm{m}$. The use of mice in this study was approved by the Massachusetts Eye and Ear Infirmary Animal Care and Use Committee and followed the ARRIVE guidelines ${ }^{46}$. 


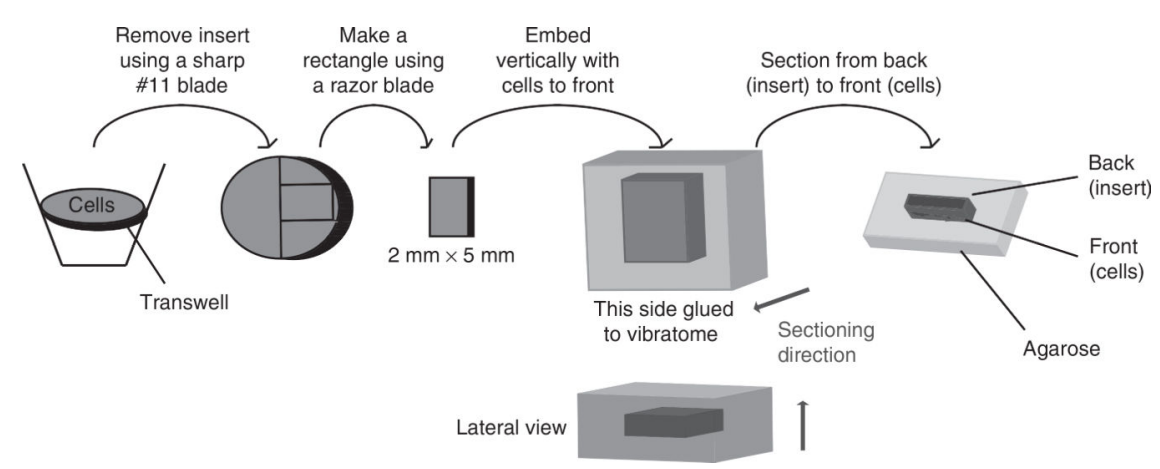

Figure $5 \mid$.

Diagram illustrating the procedure of agarose embedding and vibratome sectioning. First, remove the insert from the Transwell with a sterile \#11 carbon blade. Second, cut a small $(\sim 2 \mathrm{~mm} \times 5 \mathrm{~mm})$ piece of insert. Third, vertically embed the fragment in agarose, making sure that Front the side with the cells is located in the front. Fourth, cut the agarose block, leaving a frame of $\sim 5 \mathrm{~mm}$ surrounding the specimen. Fifth, glue the block to a vibratome by one of the short sides and with the cells on the front side so that the blade will cut the insert first and then the cells. 

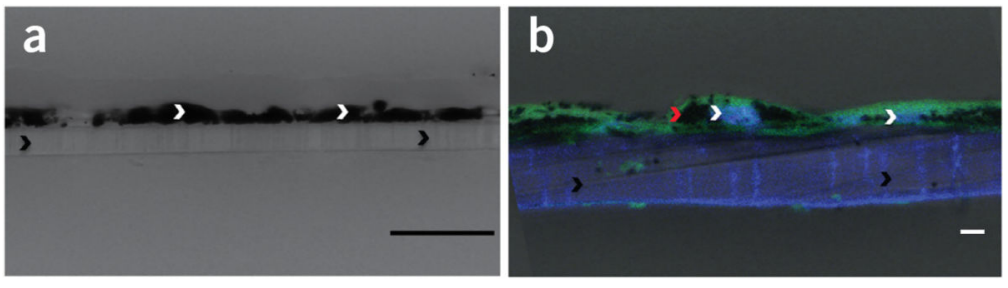

\section{Figure 6 .}

Vibratome sections of primary mouse RPE cells taken from a 2.5-month-old wild-type male C57BL/6J mouse and grown on Transwells for 2 weeks. (a) Bright-field microscopy image showing the RPE monolayer (white arrowhead) grown on a Transwell insert (black arrowhead). (b) RPE monolayer immunostained for complement C3 (green; Abcam, cat. no. AB11862; diluted 1/200 in 1\% (wt/vol) BSA) and Hoechst (blue) showing the presence of nuclei (white arrowheads) and pigmented cytoplasm (red arrowhead) in the RPE monolayer grown on a Transwell insert (black arrowheads). Images were taken with a confocal microscope. Scale bars, $5 \mu \mathrm{m}$. 

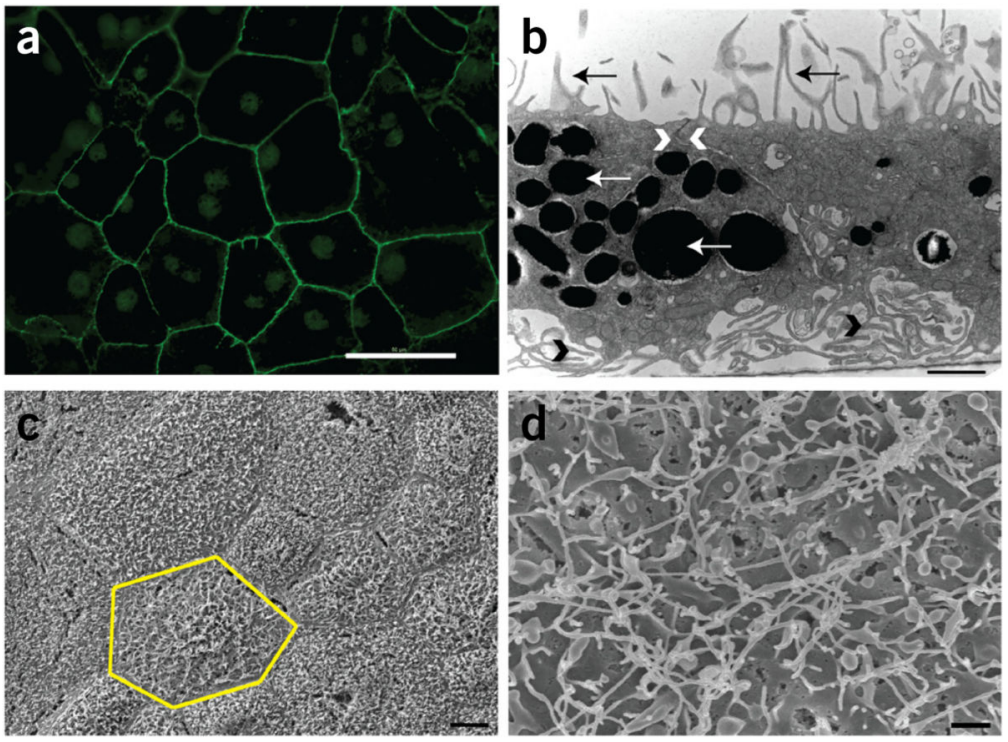

Figure $7 \mid$.

Characterization of polarized RPE cultures (a-d). Characterization of polarized RPE cultures imaged using a confocal microscope (a) and transmission (b) and scanning (c,d) electron microscopes. (a) Primary mouse RPE cultures taken from a 2.5-month-old wildtype C57BL/6J mouse and immunostained for ZO-1 (green), which indicates the presence of tight junctions, after 1 week. (b) Tight junctions (white arrowheads) between adjacent cells, apical microvilli (black arrows), basal infoldings (black arrowheads) and melanin pigment granules (white arrows) observed by TEM. (c) The hexagonal shape of the RPE cells is visible by SEM. The yellow hexagonal outline designates a single cell. (d) The structure of apical microvilli can be visualized at higher magnification $(10,000 \times)$ using SEM. Scale bars, $10 \mu \mathrm{m}(\mathbf{a}-\mathbf{c})$ and $1 \mu \mathrm{m}(\mathbf{b}, \mathbf{d})$. 


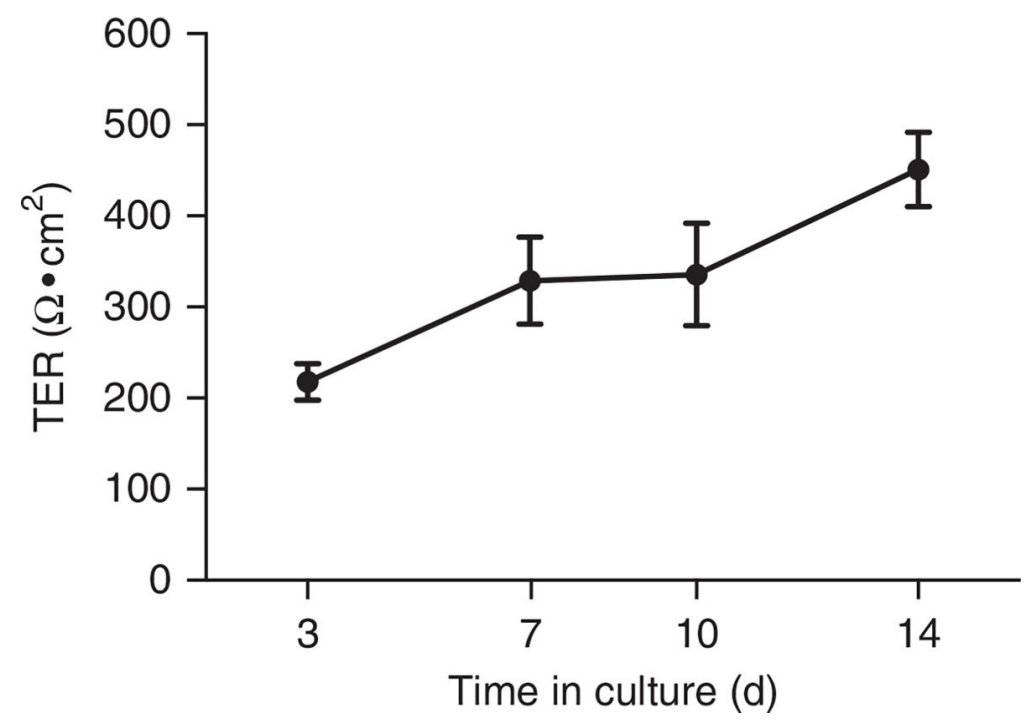

Figure 8 |.

Transepithelial electrical resistance (TER) of ten primary mouse RPE cultures measured with an EVOM epithelial tissue voltohmmeter every 3-4 d during 2 weeks in culture. RPE monolayers show high TER values that increase gradually with time in culture (values represented as mean \pm s.e.m.), reaching values over $400 \Omega \cdot \mathrm{cm}^{2}$ after 2 weeks. 
TABLE 1

Troubleshooting table

\begin{tabular}{|c|c|c|c|}
\hline Step & Problem & Possible reason & Solution \\
\hline 6 & $\begin{array}{l}\text { Retina comes up } \\
\text { through the sclera }\end{array}$ & $\begin{array}{l}\text { Sclera was pierced during removal of the } \\
\text { connective tissue }\end{array}$ & $\begin{array}{l}\text { Discard that eye. RPE cells will be damaged and } \\
\text { will not grow properly. If the sclera is just scratched } \\
\text { but the retina does not come out, RPE will be OK if } \\
\text { the eyeball remains turgid }\end{array}$ \\
\hline 9 & $\begin{array}{l}\text { Lenses cannot be } \\
\text { pulled out }\end{array}$ & The cut across the cornea is too small & $\begin{array}{l}\text { Make the cut larger. If too much pressure is applied } \\
\text { while the lens is being pulled out, it will rupture }\end{array}$ \\
\hline \multirow[t]{2}{*}{14} & $\begin{array}{l}\text { RPE remains attached } \\
\text { to the neural retina }\end{array}$ & Insufficient hyaluronidase digestion & $\begin{array}{l}\text { If mice are younger than } 4 \text { weeks, incubate eyes } \\
\text { with hyaluronidase for } 5 \text { more min }\end{array}$ \\
\hline & & Hyaluronidase was not freshly prepared & $\begin{array}{l}\text { If mice are older than } 4 \text { weeks, keep eyes on ice for } \\
\text { a further } 45 \text { min after incubation with hyaluronidase }\end{array}$ \\
\hline \multirow[t]{2}{*}{17} & $\begin{array}{l}\text { RPE cells do not } \\
\text { detach from the } \\
\text { choroid }\end{array}$ & Trypsin digestion is incomplete & $\begin{array}{l}\text { Re-incubate with trypsin for } 5 \text { more min. Ensure } \\
\text { that the eyecup is completely embedded, not } \\
\text { squeezed, and that trypsin is in contact with the RPE } \\
\text { layer }\end{array}$ \\
\hline & & Trypsin was at $4{ }^{\circ} \mathrm{C}$ for a long time & Use freshly thawed trypsin every time \\
\hline \multirow[t]{3}{*}{26} & $\begin{array}{l}\text { Cells do not attach to } \\
\text { the Transwell }\end{array}$ & It is too early & Wait for $72 \mathrm{~h}$ for complete attachment \\
\hline & & Cells were damaged during isolation & $\begin{array}{l}\text { After } 72 \mathrm{~h} \text {, if the cells are not attached, discard and } \\
\text { repeat isolation }\end{array}$ \\
\hline & & Transwell was coated with laminin for $<2 \mathrm{~h}$ & \\
\hline \multirow[t]{2}{*}{27} & $\begin{array}{l}\text { Cells lose } \\
\text { pigmentation after } \\
\text { some days in culture }\end{array}$ & Mouse-related problem & Discard the cells and isolate more \\
\hline & & $\begin{array}{l}\text { Cell density is low because many cells died during } \\
\text { the isolation process }\end{array}$ & Pool more eyes \\
\hline $\begin{array}{l}\text { Box } 1 \\
\text { (step } \\
6)\end{array}$ & $\begin{array}{l}\text { Inserts come out of the } \\
\text { agarose at sectioning }\end{array}$ & $\begin{array}{l}\text { Sections were not properly embedded in the } \\
\text { agarose }\end{array}$ & $\begin{array}{l}\text { Cut a new piece of Transwell and repeat the process } \\
\text { Temperatures must be exactly as indicated, and the } \\
\text { insert must be blotted to remove excess liquid that } \\
\text { will impede embedding }\end{array}$ \\
\hline
\end{tabular}

